INGRID DE SAINT-GEORGES

\title{
MULTILINGUALISM, MULTIMODALITY AND THE FUTURE OF EDUCATION RESEARCH
}

\section{EDUCATION IN TIMES OF CHANGE}

The labels 'post-modern condition', 'late modernity', and 'superdiversity' (Vertovec 2007) are some of the terms used in the discourse of researchers in the social sciences and humanities to capture aspects of the transformations and new conditions evident in today's developed societies. These transformations can be seen in a great many areas of social life but two examples suffice to give a glimpse of their extent.

The first has to do with changes in patterns of mobility and migration in a 'globalized' world. A generation or two ago, immigrating most often meant restricted contact with the home country, assimilation into host community norms and values, and lasting settlement in the new place. Now the picture is much more fluid and complex. Migrants today often have a footing in more than one community; they have more complex geographical and biographical trajectories; and the communities they join are less unified than previously believed. In addition, it is not only migrants who exhibit transnational behaviors; 'locals' do too. Tarrow (2005: xiii), for example, uses the term 'rooted cosmopolitans' for those individuals who grow up and remain firmly rooted in one place but who increasingly take part in global flows of information, communication, solidarities or contentions through travel, work or digital media experiences. In the globalized era, transnational connections are thus increasingly 'taken to new levels' and 'shaped in new forms' (Tarrow 2005: xiii).

The second example of profound transformation affecting contemporary societies is associated with the development of information and communication technologies. From an economic perspective, these new technologies are the source of new kinds of productivity and organizational forms, and of the development of a global economy. At the individual level, they also make possible 'texts', 'relations' and 'actions' (Jones \& Hafner 2012) that, previously, simply did not exist. Social media for example allow interactions in virtual environments with people never encountered face-to-face and who reside in distant geographical locations. Such media permit the fast spread of news to a large audience by tweeting and retweeting a line of information. They allow simultaneous off- and on-line conversations, the exertion of political pressure on governments through on-line petitions, management of one's bank account without leaving home, and so on. In this digital era, new media bring challenges to, among other things, existing

I. de Saint-Georges, J.-J. Weber (eds.), Multilingualism and Multimodality: Current Challenges for Educational Studies, 1-8.

(C) 2013 Sense Publishers. All rights reserved. 
notions of work, learning, identity, literacy, social networks, bodies, gender, generation, ethnicities, agency, time and geographical space. New media transform not only "the way [people] communicate but also "who they can be" and the kinds of relationships they can have with others' (Jones \& Hafner 2012: 1).

These late-modern conditions create a great many interesting challenges as they are of course reflected in the classroom and other sites of learning. Conditions of 'superdiversity' (Vertovec 2007) for example - 'more people moving to more places, with more complex social formations ensuing, ${ }^{1}$ - mean that, in educational institutions, varied practices, linguistic repertoires, and symbolic and economic resources come into contact, posing questions about how these institutions choose to deal with this diversity and how digital technologies transform the classroom. Visual and multimodal texts for example redefine what counts as knowledge, how it can be presented, engaged with and produced. With these transformations, the meaning of teaching, learning, interpreting and assessing demands reconsideration.

It was in order to open up talk on these changing conditions that we invited the contributors to communicate on multilingualism and multimodality. Although multilingualism and multimodality are on the surface seemingly unrelated, we expected that they would constitute useful vantage points from which to observe and describe some of the changing experiences and priorities brought to educational sites by the new social order.

\section{MULTILINGUALISM AND MULTIMODALITY: DIVERSE READINGS}

\section{Overview of the chapters}

Two kinds of readings of the texts assembled in this volume are possible (Handler 2012). One is a scaled-down, 'episodic' kind of reading. We might go into the arguments of the various chapters and find out how each in its own way reflects some particulars of the changing social order and the consequences for education and educational research. Or we can take a 'scaled up', synthetic, bird's eye view approach, reading all the texts and observing how together they construct a certain image of the conditions under which we live and in which we operate. This in turn allows us to reflect critically on the society and institutions making these conditions possible (as also suggested by Kress, this volume). We begin with the 'scaled-down' approach.

The first part of the volume - Multilingualism: concepts, practices and policies - begins by considering broadly some of the theoretical and practical consequences of ethnic, linguistic and cultural diversity as we know them now and as they are visible in educational settings. Jan Blommaert \& Ad Backus thus begin by reconsidering what it means to 'know a language'. They argue that language learning is much more eclectic and piecemeal than is often assumed and that individuals, especially those with complex track records of mobility, have in general larger and richer linguistic repertoires than is commonly thought. Assessment instruments however often fail to take into account these diverse 
repertoires, which may not be distributed homogeneously and do not necessarily coincide with the repertoires valued by the assessing authorities. Luisa Martín Rojo next examines what happens when individuals with different resources come together in the 'contact zones' (Pratt 1981: 584) produced by contemporary migration. She considers how the legitimacy of linguistic resources is established or denied, especially in contexts where such resources are unequally distributed or valued, such as the context of 'bridging classes' for newly arrived immigrants. Adrian Blackledge, Angela Creese and Jaspreet Kaur Takhi likewise discuss the limits of traditional definitions of the concepts of 'language' and 'multilingualism'. Analyzing the exchanges in heritage classrooms, they propose that research should go beyond studying the multiple competences and repertoires of multilingual learners and rather make visible the social, individual and cultural tensions and creativity that arise from belonging to multiple communities, in the sense of being able to appropriate and ventriloquate many different 'voices' at once.

The next two chapters are concerned with how language policies accommodate multilingualism (or fail to do so). Ruth Wodak first examines multilingualism within EU institutions. She explores the everyday practices of the eurocrats working in these structures and the language ideologies related to multilingualism internalized as part of their work. Wodak emphasizes that although multilingualism is such a key element for the construction of an 'inclusive and democratic Europe', there are as yet no articulated multilingual policies in the context of the EU institutions. While we might think that if such policies existed they could provide a model for other institutions which have transnationalism, migration and mobility at their heart, Jean-Jacques Weber and Kristine Horner's chapter warns us that it might be some time before a 'multilingual mindset' takes over from the 'monolingual habitus'. Their study of language policies in two multilingual universities indeed shows that even those institutions that seem most engaged in developing multilingual programs remain in fact unable to break away from an ideology of 'monolingualism as the norm'.

The chapters in the second part of the volume - Multimodality: Concepts, Practices and Consequences - are concerned with the changing communication landscape associated with the new order. They focus however not so much on the linguistic repertoires individuals deploy in educational situations but on the full range of multimodal resources made use of. These chapters also ask: what happens when material conditions and social arrangements are redefined, through the use of new technology or otherwise? Gunther Kress begins by proposing that, if one is to fully recognize the semiotic work learners do when learning, the new circumstances require new thinking about learner agency, pedagogical tools and pedagogical relations. Examples from museum exhibits and surgeries are used by Kress to reflect upon how one is to recognize and sanction what counts as 'signs of learning' in circumstances ill-adapted to evaluation by the current metrics of assessment. The multimodal social semiotic framework articulated by Kress is also taken up by Carey Jewitt. She provides a detailed case study of transformations in the teaching of English as a subject in UK classrooms across a time-span of ten years. This longitudinal approach permits us to see the interplay between 
pedagogical and social arrangements in the classroom and new media. In this chapter, Jewitt demonstrates the importance, if one wants to understand present day conditions of teaching and learning, of jointly studying technological changes, the production of curriculum knowledge and the social and cultural particulars of teaching a subject. The chapter by Laurent Filliettaz, Stefano Losa and Barbara Duc turns to the field of vocational education and training. The authors examine the difficulties experienced by apprentices of 'gaining recognition' when entering the workplace. They show that the demands made in workplace contexts are often complex and implicit, requiring access to subtle linguistic routines and non-verbal conduct. Not all apprentices come equally equipped to meet these demands and many face difficulties in their professional development and upward mobility as a consequence.

The chapters as a group take critical stock of current responses to the increased diversity, multilingualism and technological possibilities in schools and other educational institutions. In the closing section, the chapter by Ron Scollon invites us to start imagining and building the 'new geographies' that, through reflection on interconnections between individual actions and larger 'material-semiotic activity systems', will make possible new responses to new conditions.

Overall, the chapters revisit many important themes for education research, related to diversity, multilingualism, language learning, language policy, assessment and evaluation, teaching and learning, curriculum development, the place and role of new technology in the classroom, guidance and socialization. They also all seem to address an unspoken question: what adjustments and recalibrations must analysts make so that their work remains suited to the task of responding to and understanding changing educational experiences and social priorities? Some authors find traditional concepts and images still powerful, some propose that we need new ones in the light of present circumstances, yet others propose amending or reworking the coordinates used thus far. But a point made in all chapters is that approaches more consonant with today's diverse, fluid, fragmented and complex society urgently need to be developed.

\section{Key themes}

These more general comments lead to the second possible approach to reading the chapters, the 'synthetic' or 'scaled up' approach. If we take a bird's eye view, what themes stand out? The task of identifying transversal threads here is complicated by the fact that the two main themes of the volume - multilingualism and multimodality - are not automatically connected. Yet, it is instructive to attempt to adopt such a bird's eye view in order to determine the sub-themes that become visible if one does so.

Sites and sorts of learning The first interesting thing of note is that many of the authors provide rich and careful observations of 'sites' of learning not traditionally studied in applied linguistics. Alongside the studies carried out in traditional schools (Jewitt, Kress), authors in the volume examine: bridging classrooms 
(Martín Rojo), heritage/complementary schools (Blackledge et al.), multilingual universities (Weber \& Horner), vocational programs (Kress, Filliettaz et al.), museums as sites of learning (Kress) and European institutions as multilingual workplaces (Wodak). Many of these 'educational sites' are recent contexts developed in response to new patterns of mobility, migration and internationalization. In that sense, the research focus reflects the social zeitgeist.

At the same time, it is also interesting that more traditional places of learning have been revisited using the new tools that have become available. Take for example the focus on vocational education and the interest in embodied learning (Filliettaz et al., Kress). It is not that that previous research about these topics was non-existent but the new communicational landscape has created the need to develop a new vocabulary to talk about non-verbal modes of meaning-making, and this new vocabulary has now become available to describe embodied forms of learning and to 'rediscover' the characteristics of older teaching and learning practices such as apprenticeships. With these multimodal approaches to learning, it becomes possible, for example, to investigate situated learning in the domains of the trades and professions and also to recognize and describe, in the more formal spaces of schooling, how learning, thought, creativity and communication are processes of the whole body.

History/Histories Another theme, when we look at all the texts assembled in the volume, concerns methodology. While they inscribe themselves in different traditions and draw concepts from different disciplines (social semiotics, critical discourse analysis, interactional sociolinguistics, discourse analysis, sociology, literary criticism, etc.), the texts have at least one common point. All stress in one way or another the importance of incorporating 'history/histories' into the research process. Jewitt and Kress for example both adopt a contrastive perspective, comparing schools 'then' and 'now' as a means of capturing how societal changes have affected the organisation of schooling and the resources available for teaching and learning. Kress, Blommaert \& Backus, and Filliettaz et al. focus on the learning processes through which skills and repertoires come to be integrated in the biographical trajectory of individuals. Blackledge et al. investigate how past voices and discourses resonate in the exchanges of learners from migrant backgrounds, and how these historically-loaded voices make possible a playing with identities, along with the adoption of different positionings and displays of 'authenticity'. Martín Rojo underlines that newcomers to bridging schools do not come as blank slates but with a set of values internalized at other educational institutions. This primary habitus provides a context for learning that is sometimes at odds with what the new context has to offer in terms of content or procedures. Wodak insists on the necessity of always considering different layers of context when analyzing any piece of discourse and shows how these layers exist on different timescales, while Weber \& Horner similarly ensure that their analysis of language policies integrates understanding of the larger socio-historical context in which the policies were produced. The chapters thus all seem to point to the fact that the rapid changes experienced today are best understood by looking at the consequences of social and 
political history for individual histories. Awareness of history/histories helps our understanding of how things have come to be the way they are; it helps us understand the continuities and discontinuities in individuals' lives as well as in the social organization of these lives; it permits us to name some of the practices that serve to create or erase differences between groups. Without historical understanding, the authors seem to suggest, our insights into teaching and learning processes or policies can quickly become shallow and fleeting.

Multilingual Repertoires and Multimodal Resources. A third observation that can be made when we look at the volume as a whole is that none of the chapters venture into any explicit discussion of how its two main themes - multilingualism and multimodality - are to be connected.

In the first half of the volume, the chapters converge in discussing the conceptions of 'language' and of 'multilingualism' best suited to current circumstances. Contributions by Blommaert \& Backus, Martín Rojo, Blackledge et al., Wodak, Weber \& Horner make the case that folk models that hold languages to be discrete, bounded entities are ill-suited to making sense of the mixed multilingual practices, creolization, code-meshing, continuities across varieties, etc., typical of the current cosmopolitan context. Yet these models are prevalent in mainstream discourse and contribute effectively to reproducing an ideology that sees monolingualism as the 'norm' and multilingualism as the 'odd case' (Weber $\&$ Horner). Since many learners in contemporary classrooms have in fact large repertoires at their disposal, these authors warn, we need to watch how the 'monolingual mindset' plays out in limiting access and in the expression of voice.

In the second half of the volume, it is a reflection on the multiple modes in which learning can be presented and shaped that is foregrounded. Here for example, Kress vividly makes the point that teachers and educators need to become better at detecting evidence of learning, especially when 'signs of learning' do not come in canonical or traditionally expected forms. Authors in this part of the volume (Kress, Jewitt, Filliettaz et al.) concur that verbocentric perspectives on teaching and learning are not well adapted to do that detection.

If we seek to connect the two parts of the book, what becomes apparent is that it is not just learners' multilingual repertoires that speak of their mobility across spaces, of the learning opportunities that were given to them, of the people they have encountered and of the kinds of milieus and environments they have traversed (Blommaert \& Backus), but their repertoires of (multimodal) practices also speak of these (Kress, Filliettaz et al, Jewitt, Martín Rojo, Blackledge et al.). This means that more studies are needed to look jointly at, on the one hand, the resources multilingual repertoires constitute for constructing knowledge, pedagogical relations, texts and actions and, on the other, at the manner in which texts, tools, actors, spaces, technologies, etc. mediate the learning and appropriation of multilingual repertoires.

Valuation/Recognition A final thread developed by several authors across the two parts of the volume, even though it is treated in quite different ways, is the theme 
of 'recognition' (see Kress, Filliettaz et al., Martín Rojo for the most prominent discussions of this theme, but also related arguments in Wodak, Weber \& Horner, Blackledge et al. and Blommaert \& Backus).

Recognizing something, Kress argues, has different meanings. It might mean simply to 'see it', acknowledge it or give it credit, or it might imply distinguishing its worth (as when one gives an award in 'special recognition' of some accomplishment). In that sense, Kress argues, recognition integrates the idea of 'value' and 'valuation'. When diverse practices come into contact, the question of 'recognition' and 'valuation' almost always takes center stage: which practices get recognized? And by whom? Which practices allow one to gain recognition and how? Which practices are 'devalued' or 'delegitimized' and for what purposes? The chapters collectively show that ideologies of assimilation and conformism to a specific set of social norms are reinforced (a situation often found in formal schooling institutions) when the option of taming diversity is taken. But the chapters also show that, even in situations where diversity is in principle appreciated and encouraged, different weight is still given to different practices. In other words, even when the social and cultural market seems open, not all practices are valued equally.

This links to another line of discussion. To a large extent, the focus in all the texts is very much on detecting where the center of authority is in educational sites and institutions, as well as on how hierarchies are played out and differences emphasized. It is on reflecting how a different balance of power could be imagined or enacted. As O'Reilly (1993) has pointed out, we have become quite good at investigating how devaluation works, but have been less busy observing consensus, pluralism, unity in diversity, etc. and less savvy at detecting the mechanisms and patterns behind 'respectful' attitudes. With Adam and Groves (2007: 152) we could perhaps suggest that what might be needed to develop this shift of balance is another social model for schools and educational institutions, not one based on the presumption of equality, but one based on an 'ethics of care'. Such an ethics, Adam and Groves argue, means that we do not operate on the assumption that we should perform certain tasks and encourage certain relationships with others because those others are of equal value to ourselves, but because they are of 'special and unique value', and because it means something to us personally that those others realize the futures they project for themselves, since our futures and theirs are inextricably bound. This brings us to our closing discussion.

\section{THE FUTURE OF EDUCATION RESEARCH}

In conducting careful empirical observations and analyses of interactions in superdiverse, and/or technologically complex environments, the authors of the contributions assembled in this volume contribute something important: they give a shape - a semiotic form - to some of the issues raised by transnational migration, sociocultural complexity, and the new social order. The chapters provide 'images, more or less detailed or sketched, of present social arrangements and conditions' (Kress, this volume). Through these images, the authors help make visible changes 
in progress; they provide evidence of the social, cultural and political challenges associated with the new order; they help us to see which ideologies are strengthened or remodelled in the new context. They also importantly work at identifying the kinds of new questions and new terrains that can and must be explored in this new context. So one major way in which the chapters address 'the future of education' research - the focus of the book series to which this volume contributes - is by identifying new directions for investigation.

But by building images of current social arrangements, the chapters also do something else. They set the readers thinking: are the social arrangements identified the preferred ones or could alternative, possibly more desirable, scenarios be entertained? Following Gee (1998: 22), the chapters propose that 'one way we can analyze people, words, and deeds is to ask what they seek to pro-ject into the world, what political projects they implicate'. At the end of this volume, we are left with the understanding that one of the tasks that lies ahead with regard to the future of education research is to make more visible which social arrangements work 'to limit our imagination' and which ones 'play out in funnelling opportunities for experience of a different kind' (R. Scollon 2002). This experience may be one in which we show more care for others in this world of diversity and in which we acknowledge their special and unique value to us, rather than attempting to tame or make invisible the diversity of repertoires and practices.

\section{NOTES}

1 As summarized in the presentation of the research project on 'superdiversity' http://www.mmg.mpg.de/research/all-projects/super-diversity/

\section{REFERENCES}

Adam, B., \& Groves, C. (2007). Future matters: Action, knowledge, ethics. Leiden and Boston: Brill.

Gee, J. P. (1998). The New Literacy Studies: from 'socially situated' to the work of the social. Paper presented at 'Situated literacies', Lancaster, UK. 8-10 July.

Handler, R. (2012). What's up, Doctor Goffman? Tell us where the action is! Journal of the Royal Anthropological Institute 18, 179-190.

Jones, R. H., \& Hafner, C. (2012). Understanding digital literacies: A practical introduction. London and New York: Routledge.

O’Reilly, M.R. (1993). The peaceable classroom. Portsmouth, NH: Boynton/Cook Publishers.

Pratt, M. L. (1991). Arts of the contact zone. Modern Language Association, 33-40.

Scollon, R. (2002a). What's the point? Can mediated discourse analysis stop the war? Accessed April 2003 at http://www.gutenbergdump.net/mdp/point.htm

Tarrow, S. (2005). The new transnational activism. Cambridge: Cambridge University Press.

Vertovec, S. (2007). Super-diversity and its implications. Ethnic and Racial Studies 30, 1024-1054.

Ingrid de Saint-Georges

University of Luxembourg 